Virginia Commonwealth University

VCU Scholars Compass

2001

\title{
Control of Vancomycin-Resistant Enterococcus in Health Care Facilities in a Region
}

Belinda E. Ostrowsky, M.D., M.P.H.

Virginia Commonwealth University, National Center for Infectious Diseases, bostrow@hsc.vcu.edu

William E. Trick

National Center for Infectious Diseases

Annette H. Sohn

National Center for Infectious Diseases

See next page for additional authors

Follow this and additional works at: http://scholarscompass.vcu.edu/vcuhealth_pubs

Part of the Medicine and Health Sciences Commons

From The New England Journal of Medicine, Ostrowsky, B. E., Trick, W. E., Sohn, A. H. et al., CONTROL OF VANCOMYCIN-RESISTANT ENTEROCOCCUS IN HEALTH CARE FACILITIES IN A REGION, Vol. 344, Page 1427, Copyright () 2001 Massachusetts Medical Society. Reprinted with permission.

\section{Downloaded from}

http://scholarscompass.vcu.edu/vcuhealth_pubs/21

This Article is brought to you for free and open access by the VCU Health at VCU Scholars Compass. It has been accepted for inclusion in VCU Health Publications by an authorized administrator of VCU Scholars Compass. For more information, please contact libcompass@vcu.edu. 
Authors

Belinda E. Ostrowsky , M.D., M.P.H.; William E. Trick; Annette H. Sohn; Stephen B. Quirk; Stacey Holt , B.S.; Loretta A. Carson, M.S.; Bertha C. Hill; Mathew J. Arduino; Mathew J. Kuehnert; and William R. Jarvis 


\title{
CONTROL OF VANCOMYCIN-RESISTANT ENTEROCOCCUS IN HEALTH CARE FACILITIES IN A REGION
}

\author{
Belinda E. Ostrowsky, M.D., M.P.H., William E. Trick, M.D., Annette H. Sohn, M.D., Stephen B. Quirk, M.P.P., \\ Stacey Holt, M.M.Sc., Loretta A. Carson, M.S., Bertha C. Hill, B.S., Matthew J. Arduino, Ph.D., \\ MATTHEW J. Kuehnert, M.D., AND William R. JARVIS, M.D.
}

\begin{abstract}
Background In late 1996, vancomycin-resistant enterococci were first detected in the Siouxland region of lowa, Nebraska, and South Dakota. A task force was created, and in 1997 the assistance of the Centers for Disease Control and Prevention was sought in assessing the prevalence of vancomycin-resistant enterococci in the region's facilities and implementing recommendations for screening, infection control, and education at all 32 health care facilities in the region.

Methods The infection-control intervention was evaluated in October 1998 and October 1999. We performed point-prevalence surveys, conducted a casecontrol study of gastrointestinal colonization with vancomycin-resistant enterococci, and compared infection-control practices and screening policies for vancomycin-resistant enterococci at the acute care and long-term care facilities in the Siouxland region.

Results Perianal-swab samples were obtained from 1954 of 2196 eligible patients (89 percent) in 1998 and 1820 of 2049 eligible patients (89 percent) in 1999. The overall prevalence of vancomycin-resistant enterococci at 30 facilities that participated in all three years of the study decreased from 2.2 percent in 1997 to 1.4 percent in 1998 and to 0.5 percent in $1999(\mathrm{P}<0.001$ by chi-square test for trend). The number of facilities that had had at least one patient with vancomycinresistant enterococci declined from 15 in 1997 to 10 in 1998 to 5 in 1999. At both acute care and long-term care facilities, the risk factors for colonization with vancomycin-resistant enterococci were prior hospitalization and treatment with antimicrobial agents. Most of the long-term care facilities screened for vancomycin-resistant enterococci (26 of 28 in 1998 [93 percent] and 23 of 25 in 1999 [92 percent]) and had infection-control policies to prevent the transmission of vancomycin-resistant enterococci (22 of 25 [88 percent] in 1999). All four acute care facilities had screening and infection-control policies for vancomycinresistant enterococci in 1998 and 1999.

Conclusions An active infection-control intervention, which includes the obtaining of surveillance cultures and the isolation of infected patients, can reduce or eliminate the transmission of vancomycinresistant enterococci in the health care facilities of a region. (N Engl J Med 2001;344:1427-33.)

Copyright (@) 2001 Massachusetts Medical Society.
\end{abstract}

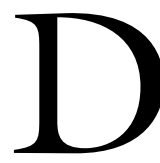
URING the past decade, vancomycinresistant enterococci have emerged and become endemic at many health care facilities in the United States. ${ }^{1-6}$ A major impediment to control is the large, unrecognized population of patients who are colonized with vancomycin-resistant enterococci and who thus can serve as a reservoir for transmission..$^{7-9}$ Colonization with vancomycinresistant enterococci has been associated with progression to infection. ${ }^{8}$ Studies suggest that once vancomycin-resistant enterococci are introduced in a facility, and particularly after they have spread to multiple patients or wards, control is very difficult. ${ }^{6-8}$

Between December 1996 and April 1997, the number of isolates of vancomycin-resistant enterococci increased from 0 to 63 at health care facilities in the Siouxland region of Iowa, Nebraska, and South Dakota, which has a population of 135,000 . A task force was formed, and in July 1997 the Hospital Infections Program of the Centers for Disease Control and Prevention (CDC) was invited to assist in an investigation. The prevalence of vancomycin-resistant enterococci at the 32 facilities ( 4 acute care and 28 long-term care facilities) in the region was determined, and risk factors for vancomycin-resistant enterococci were assessed..$^{10}$ On the basis of these findings, an intervention program was initiated. We returned on October 5, 1998, and October 25, 1999, to determine the prevalence of gastrointestinal colonization with vancomycin-resistant enterococci 14 and 26 months, respectively, after the initial prevalence survey and to evaluate the effect of the intervention.

\section{METHODS}

\section{The Task Force}

In spring 1997, a meeting with representatives of health care facilities in the Siouxland region of Iowa, Nebraska, and South Dakota was held to discuss the sudden increase in the number of isolates of vancomycin-resistant enterococci at these facilities, and a task force was formed that included public health workers and personnel from acute care and long-term care facilities. On the basis of the initial results, ${ }^{10}$ a strategy to decrease the transmission

From the Hospital Infections Program, National Center for Infectious Diseases (B.E.O., W.E.T., A.H.S., S.H., L.A.C., B.C.H., M.J.A., M.J.K., W.R.J.), and the Epidemic Intelligence Service, Division of Applied Public Health Training, Epidemiology Program Office (B.E.O., W.E.T., A.H.S., M.J.K.), Centers for Disease Control and Prevention, Atlanta; and the Siouxland District Health Department, Sioux City, Iowa (S.B.Q.). Address reprint requests to Dr. Ostrowsky at the Medical College of Virginia Campus of Virginia Commonwealth University, Epidemiology and Infection Control Unit, 1200 E. Broad St., West Hospital, East Wing Rm. 202B, P.O. Box 980019, Richmond, VA 23298, or at bostrow@hsc.vcu.edu. 
of vancomycin-resistant enterococci was developed. The guidelines of the task force ${ }^{11}$ were adapted from the CDC recommendations ${ }^{12}$ (Table 1). In April 1998, after review by the Hospital Infections Program of the CDC and the Iowa Department of Health, the guidelines were disseminated to all 32 health care facilities in the Siouxland region.

\section{Study Participants}

In collaboration with the Siouxland District Health Department, the task force, the state health departments of the three states involved, and the Indian Health Service, we invited the same 32 facilities in the region that took part in the 1997 study to participate in the 1998 and 1999 studies. ${ }^{10}$ Eligible participants included all nonpsychiatric inpatients who were 18 years of age or older. All samples were collected by using premoistened swabs during three successive days in both 1998 and 1999. Each patient was assigned a number by the facility personnel and was not identified by name. At the time of sample collection, oral consent was obtained.

\section{Microbiologic Methods}

A perianal swab, defined as a swab taken from the anal verge, without rectal insertion, was obtained from all participants except those with a colostomy or ileostomy stoma. Swabs from the latter patients were obtained from the junction of the epidermal and the mucosal surfaces. All swabs were streaked onto bile esculin azide with agar medium containing $6 \mu \mathrm{g}$ of vancomycin per milliliter (Becton Dickinson, Cockeysville, Md.) and incubated at $35^{\circ} \mathrm{C}$ for 48 hours. Colonies with morphologic features consistent with those of enterococcus were transferred to blood-agar slants and transported to the CDC for microbiologic confirmation as enterococcus and identification of the species, ${ }^{13}$ vancomycin-susceptibility testing,,$^{14}$ and molecular typing by pulsed-field gel electrophoresis. ${ }^{15}$ Isolates of vancomycin-resistant enterococci that were obtained during our surveys in 1998 and 1999 were compared with isolates obtained during the initial survey in 1997 and with isolates obtained in late 1996 and 1997 that were requested in 1998 from three medical centers within 160 to $480 \mathrm{~km}$ (100 to $300 \mathrm{mi}$ ) of Sioux City, Iowa.

\section{Epidemiologic Studies}

In October 1998, a case-control study was conducted to assess risk factors for gastrointestinal colonization with vancomycin-resistant enterococci. A patient was defined as any patient in a health care facility of the Siouxland District Health Department who was found to have gastrointestinal colonization with vancomycin-resistant enterococci during the point-prevalence survey. Control pa-

Table 1. Guidelines for the Care of Patients with Vancomycin-Resistant Enterococci Who Are in Acute Care and Long-Term Care Facilities.*

\section{INTERVENTION \\ Screening (by the culture of perianal swabs) On admission \\ At discharge \\ At other times \\ At time at which termination \\ of precautions is considered \\ Isolation and infection-control \\ precautions \\ Room assignment}

Acute Care Faciutty

Vancomycin-resistant enterococci status

Barrier precautions

Hand washing

Care of equipment

Education

Communication within facilities
Patients who are transferred from acute care facilities outside the community

Not recommended for patients who are being discharged to long-term care facilities, if stay was less than $72 \mathrm{hr}$ and patient did not receive antimicrobial agents

Patients at high risk (if indicated) $\dagger$

Follow CDC recommendations ${ }^{12} \ddagger$

Private or with other patients positive for vancomycinresistant enterococci

System of identifying the records of patients with infection or colonization

Use of gloves for direct patient contact; use of gowns for substantial contact with patient and patient's body fluids Health care workers, patients, and visitors

Dedicated use of noncritical equipment; cleaning or disinfecting of equipment with approved disinfectants

Educational materials provided for health care workers, patients, and visitors

Vancomycin-resistant enterococci status of patient indicated orally and written on transfer sheets
Long-Term Care Facility

Patients who are admitted from acute care facilities whose vancomycin-resistant enterococci status is unknown should be evaluated for risk factors $†$ and screened if appropriate; contact precautions should be implemented until final results are known

No recommendations

Patients at high risk (if indicated) $\uparrow$

Follow CDC recommendations ${ }^{12} \ddagger$

Private or with other patients positive for vancomycinresistant enterococci; can share room with a patient negative for vancomycin-resistant enterococci if both patients meet specific criteria $\$$

System of identifying the records of patients with infection or colonization

Use of gloves for direct patient contact; use of gowns for substantial contact with patient and patient's body fluids Health care workers, patients, and visitors

Dedicated use of noncritical equipment; cleaning or disinfecting of equipment with approved disinfectants

Educational materials provided for health care workers, patients, and visitors

Vancomycin-resistant enterococci status of patient indicated orally and written on transfer sheets

*Adapted from the recommendations of the Siouxland Vancomycin-Resistant Enterococci Task Force.11

†Patients at high risk are patients who have been hospitalized longer than 72 hours, those with clinically significant underlying medical conditions (patients undergoing dialysis, patients with cancer, and transplant recipients), those in intensive care, and those undergoing prolonged treatment with antimicrobial agents or with invasive devices.

$\ddagger$ A change in health status or treatment with antimicrobial agents may warrant the reestablishment of precautions.

\$The following criteria (listed in order of importance) must be met: roommate cannot be immunosuppressed or have broken skin or renal failure; roommate and patient who is positive for vancomycin-resistant enterococci must be coherent and able to wash their hands and observe other infection-control practices; patient who is positive for vancomycin-resistant enterococci cannot have diarrhea, urinary incontinence, or draining wound. 
tients without gastrointestinal colonization with vancomycin-resistant enterococci were randomly selected from facilities that had patients with colonization. Patients and controls were compared with regard to demographic characteristics, clinical and functional status, prior admission to a health care facility, and prior treatment with antimicrobial agents..$^{8,9,16-19}$

\section{Site Visits and Infection-Control Assessment}

In 1998, site visits were performed at acute care and long-term care facilities to review the policies of each facility regarding the control of vancomycin-resistant enterococcal infections and compare them with the answers to previously distributed institutional questionnaires. In 1999, a follow-up infection-control questionnaire was administered. The rates of screening of patients for vancomycin-resistant enterococci, isolation or grouping ("cohorting") of patients colonized or infected with vancomycin-resistant enterococci, and infection-control policies in 1997, 1998, and 1999 were compared.

\section{Use of Antimicrobial Agents}

On the day of the site visit to a long-term care facility, staff members were asked to provide the number of patients during the previous week who had been prescribed antimicrobial agents. One acute care facility in Sioux City was also asked to provide the number of patients admitted and the number prescribed vancomycin in 1997 (before the intervention) and 1998 (after the intervention).

\section{Statistical Analysis}

Data were collected on standardized forms, entered into the computer, and analyzed with use of Epi Info (version 6.03, CDC, Atlanta) and SAS software (version 6.12, SAS Institute, Cary, N.C.). The prevalence rates for each year were compared with the use of a crude chi-square test, Mantel-Haenszel adjusted chi-square test, and a chi-square test for trend. For the case-control study, categorical variables were compared with the use of the Mantel-Haenszel chi-square test, with each facility considered as a stratum. Odds ratios and 95 percent confidence intervals were calculated.

\section{RESULTS}

\section{Characteristics of the Facilities and Patients}

All 32 health care facilities located within $80 \mathrm{~km}$ $(50 \mathrm{mi})$ of Sioux City participated in the survey of the prevalence of vancomycin-resistant enterococci in 1998, and 30 (4 acute care and 26 long-term care facilities) participated in 1999. Of the 32 health care facilities, 13 of the 28 long-term care facilities (46 percent) and 2 of the 4 acute care facilities (50 percent) were located in the Sioux City metropolitan area. Two of the four acute care facilities were referral centers for regional community hospitals; these two facilities had intensive care, burn, and cardiothoracicsurgery units.

We collected swabs from 1954 of 2196 eligible patients in 1998 (89 percent) and 1820 of 2049 eligible patients in 1999 (89 percent). The overall and facilityspecific rates of participation were similar in 1997, 1998, and 1999 (Table 2). Infection-control personnel in the acute care facilities reported that patients in obstetrics and surgery wards frequently declined to participate or were unavailable because the day of the survey was the day of their procedure. Eleven of the long-term care facilities in both 1998 and 1999 had participation rates of 100 percent.

\section{Prevalence of Vancomycin-Resistant Enterococci}

Twenty-nine patients were identified as being colonized with vancomycin-resistant enterococci in 1998 (overall prevalence, 1.5 percent) and nine in 1999 (overall prevalence, 0.5 percent). All isolates were Enterococcus faecium, with minimal inhibitory concentrations of vancomycin of at least $256 \mu \mathrm{g}$ per milliliter. In the 30 facilities that participated in all three years of the survey, there were 40 patients with colonization with vancomycin-resistant enterococci in 1997 (2.2 percent), 26 in 1998 (1.4 percent), and 9 in 1999 (0.5 percent). The two facilities that chose not to participate in 1999 had no patients who were colonized with vancomycin-resistant enterococci in 1997 and had three patients who were colonized in 1998. When we compared the prevalence rates in 1997 with those in 1998 and with those in 1999, the overall rates and the facility-specific rates had decreased (Table 3 ).

In 1997, 15 facilities ( 3 acute care and 12 longterm care facilities) had at least one patient with vancomycin-resistant enterococci. In contrast, 10 facilities ( 3 acute care and 7 long-term care facilities) in

Table 2. Rates of Participation in the Survey of the Prevalence of Vancomycin-Resistant Enterococci by Facilities in the Siouxland Region in July and August 1997, October 1998, ANd OCtober 1999.*

\begin{tabular}{|c|c|c|c|c|c|c|}
\hline \multirow[t]{2}{*}{ TYPE OF FACILITY } & \multicolumn{2}{|r|}{1997} & \multicolumn{2}{|r|}{1998} & \multicolumn{2}{|r|}{1999} \\
\hline & $\begin{array}{c}\text { NO. } \\
\text { ELIGIBLE }\end{array}$ & $\begin{array}{c}\text { NO. } \\
\text { CULTURED (\%) }\end{array}$ & $\begin{array}{c}\text { NO. } \\
\text { ELIGIBLE }\end{array}$ & $\begin{array}{c}\text { NO. } \\
\text { CULTURED (\%) }\end{array}$ & $\begin{array}{c}\text { NO. } \\
\text { ELIGIBLE }\end{array}$ & $\begin{array}{c}\text { NO. } \\
\text { CULTURED (\%) }\end{array}$ \\
\hline All & 2266 & $1934(85)$ & 2196 & $1954(89)$ & 2049 & $1820(89)$ \\
\hline Acute care & 286 & $152(53)$ & 315 & $165(52)$ & 289 & $170(59)$ \\
\hline Long-term care & 1980 & $1782(90)$ & 1881 & $1789(95)$ & 1760 & $1650(94)$ \\
\hline
\end{tabular}

*A total of 32 facilities ( 4 acute care and 28 long-term care facilities) participated in the 1997 and 1998 surveys, and a total of 30 facilities (4 acute care and 26 long-term care facilities) participated in the 1999 survey. 
Table 3. Prevalence of Colonization with Vancomycin-Resistant Enterococci among Patients or Residents of 30 Acute Care and Long-Term Care Facilities in the Siouxland Region in July and August 1997, October 1998, and October 1999.*

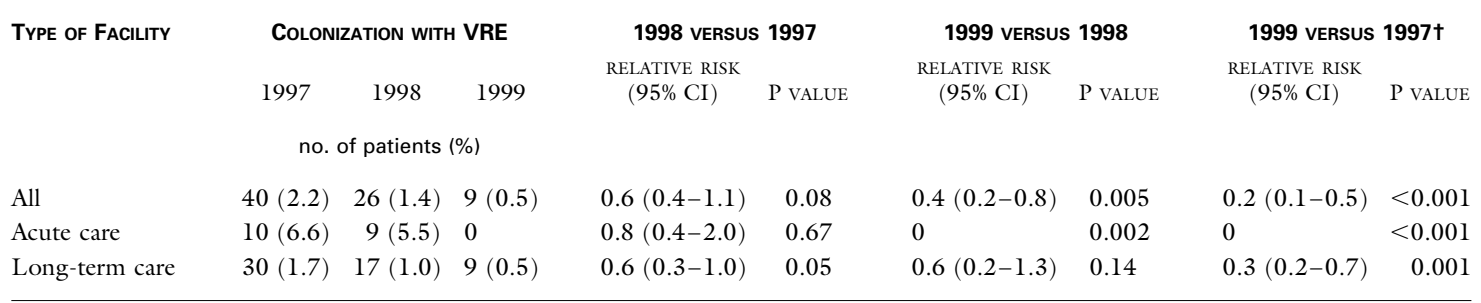

* Only data from the 30 facilities that participated in all three years of the study were included. VRE denotes vancomycin-resistant enterococci, and CI confidence interval.

†The results of the chi-square test for trend for the overall rates for 1997, 1998, and 1999 were also significant $(\mathrm{P}<0.001)$.

1998 and only 5 facilities (all long-term care facilities) in 1999 had at least one patient with vancomycinresistant enterococci. In 1999, among the 17 patients with vancomycin-resistant enterococci in a long-term care facility who had been identified in the 1998 survey, 12 (71 percent) had died and 1 (6 percent) had been discharged from the facility.

\section{Case-Control Study of Risk Factors for Colonization}

In the 1998 case-control study, we compared 29 patients with vancomycin-resistant enterococci (from all 32 participating facilities) with 114 controls. When we analyzed acute care facilities, patients were significantly more likely than controls to have been in the hospital at least 3 days, to have had at least one hospital admission in the 6 months before the study, to have received a single type of antimicrobial agent for at least 14 days, to have received an extended-spectrum cephalosporin, to have had diarrhea, and to have had a urinary catheter (Table 4). Only one patient, a control, had received intravenous vancomycin.

When we compared long-term care facilities, we found that patients were significantly more likely than controls to have been admitted to a hospital in the six months before the study, to have been admitted to hospital A (the acute care facility that had the highest prevalence of vancomycin-resistant enterococci in the 1997 survey), and to have been treated with an antimicrobial agent in the six months before the study (Table 5). None of the patients or controls in long-term care facilities had received vancomycin in the previous six months.

Of the two patients in a long-term care facility who had no prior hospital admission within the 12 months before the 1998 study, one had been admitted from a hospital before the 1997 study and had had urinary colonization with vancomycin-resistant enterococci before being transferred. Only one set of two patients newly identified in 1998 were in adjoin- ing rooms at one long-term care facility; no newly identified patients with colonization or infection were in the same room.

\section{Evaluation of Infection-Control Policies}

We received infection-control questionnaires from all 32 facilities in 1998 and from 29 of 30 facilities in 1999 (97 percent). In 1998, we visited 3 of 4 acute care facilities ( 75 percent) and 27 of 28 long-term care facilities (96 percent). In 1998, 24 of 32 facilities (75 percent) reported ever having had a patient who was colonized with vancomycin-resistant enterococci: 3 of 4 acute care facilities ( 75 percent) and 21 of 28 long-term care facilities (75 percent). By 1999, 26 of 29 facilities ( 90 percent) reported ever having had such a patient: all 4 acute care facilities (100 percent) and 22 of 25 long-term care facilities (88 percent).

\section{Screening and Identification of Colonized Patients with Vancomycin-Resistant Enterococci}

In 1997, the screening policies of acute care facilities were not assessed. In 1998 and 1999, all four acute care facilities reported that they used aggressive screening policies, which included screening patients at high risk, such as those undergoing hemodialysis or in intensive care units; screening patients on wards where clusters of colonization of infection with vancomycin-resistant enterococci had occurred; and screening all patients before they were discharged to a long-term care facility. In 1997, only 9 of 28 long-term care facilities (32 percent) had a policy regarding screening for vancomycin-resistant enterococci. In contrast, in 1998 and 1999, more than 90 percent reported having such a policy (26 of 28 [93 percent] and 23 of 25 [92 percent], respectively).

For both acute care and long-term care facilities, the proportion of all patients who were colonized with vancomycin-resistant enterococci who were identified by screening was significantly higher in 1998 
Table 4. Potential Risk Factors for Colonization with Vancomycin-Resistant Enterococci in Acute Care Facilities.

\begin{tabular}{|c|c|c|c|c|}
\hline Potential Risk FActor & $\begin{array}{l}\text { Patients WITH } \\
\text { CoLoNIZATION } \\
(\mathbf{N}=9)\end{array}$ & $\begin{array}{l}\text { CoNTROLS } \\
(\mathrm{N}=32)\end{array}$ & $\begin{array}{c}\text { MATChED OdDS RATIO } \\
(95 \% \mathrm{Cl})^{*}\end{array}$ & P Value \\
\hline \multicolumn{5}{|l|}{ Categorical variables } \\
\hline \multicolumn{5}{|l|}{ Exposure to health care facility - no. $(\%)$} \\
\hline $\begin{array}{l}\text { Length of stay } \geqslant 3 \text { days } \\
\text { Prior hospital admission (within } 6 \mathrm{mo} \text { ) }\end{array}$ & $\begin{array}{l}9(100) \\
9(100)\end{array}$ & $\begin{array}{l}13(41) \\
16(50)\end{array}$ & $\begin{array}{l}\text { Undefined } \\
\text { Undefined }\end{array}$ & $\begin{array}{l}0.006 \\
0.03\end{array}$ \\
\hline \multicolumn{5}{|l|}{ Exposure to antimicrobial agents } \\
\hline Treatment with a single agent for $\geqslant 14$ days & $2(22)$ & 0 & Undefined & 0.05 \\
\hline Treatment with extended-spectrum cephalosporin & $6(67)$ & $3(9)$ & $14.1(3.1-63.8)$ & 0.001 \\
\hline \multicolumn{5}{|l|}{ Clinical factors } \\
\hline Diarrhea & $3(33)$ & $2(6)$ & $16.5(1.7-164)$ & 0.006 \\
\hline Urinary catheter & $4(44)$ & $2(6)$ & $14.3(1.3-137)$ & 0.01 \\
\hline \multicolumn{5}{|l|}{ Continuous variables } \\
\hline \multicolumn{5}{|l|}{ Total days of treatment with antimicrobial agents $\dagger$} \\
\hline Median & 12 & 1 & & \\
\hline Range & $0-37$ & $0-33$ & - & 0.003 \\
\hline
\end{tabular}

${ }^{*}$ Odds ratios were derived from a Mantel-Haenszel procedure, with each facility considered as a stratum (i.e., each patient was matched to a control from the same facility). CI denotes confidence interval.

$\dagger$ The Kruskal-Wallis nonparametric test (not matched) was used.

Table 5. Potential Risk Factors (Categorical Variables) for Colonization with Vancomycin-Resistant Enterococci in Long-Term Care Facilities.

\begin{tabular}{|c|c|c|c|c|}
\hline \multirow[t]{2}{*}{ Potential Risk Factor } & $\begin{array}{l}\text { Patients WITH } \\
\text { Colonization } \\
(\mathbf{N}=\mathbf{2 0})\end{array}$ & $\begin{array}{c}\text { Controls } \\
(\mathrm{N}=\mathbf{8 2})\end{array}$ & $\begin{array}{l}\text { Matched OdDS RATIO } \\
(95 \% \mathrm{CI})^{*}\end{array}$ & P Value \\
\hline & \multicolumn{2}{|c|}{ no. $(\%)$} & & \\
\hline Prior hospital admission (within $6 \mathrm{mo}$ ) & $15(75)$ & $28(34)$ & $5.9(1.7-20.8)$ & 0.003 \\
\hline Prior admission to hospital $\mathrm{A} \dagger$ & $9(45)$ & $7(9)$ & $41.2 \ddagger$ & $<0.001$ \\
\hline $\begin{array}{l}\text { Length of stay }<6 \text { mo before positive } \\
\text { culture obtained }\end{array}$ & $8(40)$ & $18(22)$ & $2.4(0.9-4.7)$ & 0.08 \\
\hline $\begin{array}{l}\text { Treatment with antimicrobial agent } \\
\text { within preceding } 6 \text { mo }\end{array}$ & $18(90)$ & $55(67)$ & $4.6(1.1-20.4)$ & 0.04 \\
\hline
\end{tabular}

* Odds ratios were derived from a Mantel-Haenszel procedure, with each facility considered as a stratum (i.e., each patient was matched to a control from the same facility). CI denotes confidence interval.

†Hospital A is the acute care facility that had the highest rate of vancomycin-resistant enterococci in the 1997 prevalence survey.

$\ddagger$ Matched confidence intervals could not be calculated.

than in 1997 (for acute care facilities, 0 of 10 in 1997 vs. 9 of 9 in 1998, $\mathrm{P}<0.001$; for long-term care facilities, 7 of 30 in 1997 vs. 10 of 20 in $1998, \mathrm{P}=$ 0.05; data were available for 32 facilities in 1997 and 1998; data were unavailable for 1999).

\section{Infection-Control Practices}

Information about policies regarding the isolation of patients who were positive for vancomycin-resistant enterococci, the recommended precautions to take in caring for such patients, and the degree to which the policies and procedures were enforced in 1997 was mainly anecdotal. In 1998 and 1999, all 4 acute care facilities reported following the CDC recommendations, ${ }^{12}$ and most of the long-term care facilities that responded to our questions indicated that they isolated patients who were positive for vancomycin-resistant enterococci or grouped them together $(21$ of 23 in 1998 [91 percent]; 22 of 25 in 1999 [88 percent]). In 1999, 2 of the 22 long-term care 
facilities with policies (9 percent) required patients who were positive for vancomycin-resistant enterococci to be isolated in their rooms at all times and staff members to adhere strictly to contact precautions. Twenty long-term care facilities (9l percent) modified the CDC recommendations by allowing such patients to go outside their rooms for individual or group activities if they were capable of washing their hands and either were continent of stool or had their body fluids contained; providing ways to clean equipment used by these patients outside their rooms, such as wheelchairs; or encouraging the use of waterless hand sanitizers for workers and patients in lieu of stringent isolation.

\section{Use of Antimicrobial Agents}

Among patients in long-term care facilities, a median of 8 percent in 1998 (range, 0 to 18 percent) and 7 percent in 1999 (range, 2 to 23 percent) had been treated with antimicrobial agents within the week before the infection-control visit. Data on the use of intravenous vancomycin that were provided by one acute care facility in Sioux City showed a decrease in vancomycin use from 1997 (483 of 11,658 admissions [4.1 percent]) to 1998 (383 of 11,677 admissions [3.3 percent], $\mathrm{P}<0.001)$.

\section{Molecular Epidemiologic Findings}

Genomic typing by pulsed-field gel electrophoresis was performed on 25 of 26 isolates of vancomycinresistant enterococci (96 percent) obtained in 1998 and all 9 obtained in 1999. Four genotypes accounted for all 40 of the isolates obtained in 1997,10 as compared with 10 genotypes for the 25 isolates obtained in 1998 and 7 genotypes for the 9 isolates obtained in 1999. In 1997, one clone, type A, predominated and accounted for 85 percent of the isolates. In 1998 , type A accounted for 58 percent of the isolates, and in 1999, type A was not identified.

From the 1996 and 1997 isolates of vancomycinresistant enterococci obtained from three large referral medical centers in the midwestern United States, one isolate from a facility in Iowa approximately $480 \mathrm{~km}$ (300 mi) from Sioux City was indistinguishable from type A. Isolates from the two other referral centers were not related to any of our Siouxland isolates.

\section{DISCUSSION}

In July and August 1997, we evaluated the extent of colonization with vancomycin-resistant enterococci among patients in 32 health care facilities in the Siouxland District Health Department. Because of the rapid emergence of vancomycin-resistant enterococci in 1997, a variety of control measures were implemented. In October 1998 and October 1999, we returned to evaluate the effect of the intervention.

Virtually all published reports support the hypotheses that once vancomycin-resistant enterococci are introduced, the rates of colonization and infection increase and vancomycin-resistant enterococci become endemic unless effective control measures are introduced. $2,6,9$ Thus, without intervention, the prevalence of vancomycin-resistant enterococci in Siouxland health care facilities would have been expected to increase. Instead, the overall rate of colonization decreased from 2.2 percent in 1997 to 0.5 percent in 1999 at the 30 facilities that participated in all three years of the study.

In 1995, the CDC published recommendations to prevent the emergence and spread of vancomycinresistant enterococci that included the identification and isolation of patients colonized with vancomycinresistant enterococci, hand washing by health care workers, and cleaning of the environment. ${ }^{12}$ These recommendations were written specifically for acute care facilities and may need to be modified for longterm care facilities. We found increases in the screening of patients and compliance with recommended precautions in facilities of the Siouxland District Health Department in 1998 and 1999 as compared with 1997. Despite variations in the application of the CDC recommendations at long-term care facilities, most patients who were colonized with vancomycin-resistant enterococci who were identified in our prevalence survey had already been identified by screening programs at the various facilities. By following the CDC recommendations, these health care facilities were able to turn the tide and reduce in long-term care facilities or eliminate in acute care facilities the transmission of vancomycin-resistant enterococci. They have also prevented the emergence of serious infections with vancomycin-resistant enterococci, as evidenced by the fact that there have been no bloodstream or invasive infections with vancomycin-resistant enterococci in these facilities since the intervention. In addition, the collaboration among the facilities has fostered communication and eased the transfer of patients colonized with vancomycin-resistant enterococci between facilities, in contrast to the usual limitation of access for such patients.

The risk factors for colonization with vancomycinresistant enterococci in both 1997 and 1998 were the use of antimicrobial agents and prior exposure to acute care facilities. ${ }^{10}$ The rate of use of vancomycin in these facilities is low and may have decreased further since the intervention by the task force.

There are several limitations to our study. Cultures were obtained from a smaller proportion of patients in acute care facilities than in long-term care facilities, which may have limited assessment of the prevalence of vancomycin-resistant enterococci in these facilities. However, participation rates were similar in 1997, 1998, and 1999, and cultures were obtained from most patients at high risk. In the only acute care facility that had closed a unit because of infections with vancomycin-resistant enterococci in 
early 1997, cultures were obtained from 89 percent of patients.

We were able to perform all three evaluations in only 30 of the 32 facilities. However, the two longterm care facilities that did not participate in all three surveys had only about 100 residents.

As with any perianal screening for vancomycinresistant enterococci, colonization of some patients may not be detected by only one swab. However, the medium we used is part of a validated method of screening for vancomycin-resistant enterococci and is the same medium that is used by the laboratories of the participating facilities and that is recommended by the CDC for screening. ${ }^{12}$

In conclusion, we evaluated the efficacy of an infection-control strategy in an entire region that was implemented in order to prevent the emergence of an antimicrobial-resistant pathogen. The success of the intervention resulted from the collaboration among the participating health departments, the Siouxland District Health Department, and the personnel of the health care facilities. In an era of emerging antimicrobial resistance, when many facilities are abandoning efforts to control transmission, especially of vancomycin-resistant enterococci and methicillin-resistant Staphylococcus aureus, this comprehensive, communitywide health care effort should be viewed as a model for action. Our data show that comprehensive efforts to identify and isolate patients who are colonized with vancomycin-resistant enterococci can reduce the transmission of these strains and even eradicate them.

We are indebted to the personnel of the Siouxland District Health Department, the Iowa Department of Public Health, the Nebraska Department of Public Health, the South Dakota Department of Public Health, the Indian Health Service, and the VancomycinResistant Enterococci Task Force and to Dan Weakly, Kay Gunsolly, Mona Scarletta, and Marilyn Cripe in particular; to staff members at all the acute care and long-term care facilities in the Siouxland region for their assistance in the study design and specimen collection, and to Dee Pederson, Diane Prieksat, Joan Rothwell, Mike Kafka, and Gregg Galloway in particular; to Mary DiMartino, Jane Getchel, Nelson Moyer, and Michael James of the Iowa Hygienics Laboratory for laboratory support; and to Il-lun Chen and Dawn Comstock for assistance in our 1998 on-site activities.

\section{REFERENCES}

1. National Nosocomial Infections Surveillance (NNIS) System report, data summary from January 1990-May 1999, issued June 1999. Am J Infect Control 1999;27:520-32.

2. Nosocomial enterococci resistance to vancomycin - United States, 1989-1993. MMWR Morb Mortal Wkly Rep 1993;42:597-9.

3. Moellering RC. Emergence of enterococcus as a significant pathogen. Clin Infect Dis 1992;14:1173-6.

4. Eliopoulos GM. Antibiotic resistance in enterococcus species: an update. Curr Clin Top Infect Dis 1996;16:21-51.

5. Idem. Vancomycin-resistant enterococci: mechanism and clinical relevance. Infect Dis Clin North Am 1997;11:851-65.

6. Bonilla HF, Zervos MA, Lyons MJ, et al. Colonization with vancomycin-resistant Enterococcus faecium: comparison of a long-term care unit with an acute-care hospital. Infect Control Hosp Epidemiol 1997;18:3339.

7. Farr BM. Hospital wards spreading vancomycin-resistant enterococci to intensive care units: returning coals to Newcastle. Crit Care Med 1998;26: 1942-3.

8. Weinstein JW, Roe M, Towns M, et al. Resistant enterococci: a prospective study of prevalence, incidence, and factors associated with colonization in a university hospital. Infect Control Hosp Epidemiol 1996;17: 36-41.

9. Morris JG, Shay DK, Hebden JN, et al. Enterococci resistant to multiple antimicrobial agents, including vancomycin: establishment of endemicity in a university medical center. Ann Intern Med 1995;123:250-9.

10. Trick WE, Kuehnert MJ, Quirk SB, et al. Regional dissemination of vancomycin-resistant enterococci resulting from interfacility transfer of colonized patients. J Infect Dis 1999;180:391-6.

11. Siouxland VRE Task Force. Guidelines for management of patients with vancomycin-resistant enterococci. Sioux City, Iowa: Siouxland District Health Department, April 1998.

12. Recommendations for preventing the spread of vancomycin resistance: recommendations of the Hospital Infection Control Practices Advisory

Committee (HICPAC). MMWR Morb Mortal Wkly Rep 1995;44(RR-

12):1-13.

13. Facklam RR, Sahm DF. Enterococcus. In: Murray PR, ed. Manual of clinical microbiology. 6th ed. Washington, D.C.: ASM Press, 1995:30814.

14. Performance standards for antimicrobial susceptibility testing. NCCLS approved standard M100-S8. Wayne, Pa.: National Committee for Clinical Laboratory Standards, 1998

15. Lai E, Birren BW, Clark SM, Simon MI, Hood L. Pulsed field gel electrophoresis. Biotechniques 1989;7:34-42.

16. Edmond MB, Ober JF, Weinbaum DL, et al. Vancomycin-resistant Enterococcus faecium bacteremia: risk factors for infection. Clin Infect Dis 1995;20:1126-33.

17. Bonten MJ, Hayden MK, Nathan C, et al. Epidemiology of colonisation of patients and environment with vancomycin-resistant enterococci. Lancet 1996;348:1615-9.

18. Shay DK, Maloney SA, Montecalvo M, et al. Epidemiology and mortality risk of vancomycin-resistant enterococcal bloodstream infections. J Infect Dis 1995;172:993-1000.

19. Hawes C, Morris JN, Philips CD, Mor V, Fries BE, Nonemaker S. Reliability estimates for the Minimum Data Set for nursing home resident assessment and care screening (MDS). Gerontologist 1995;35:172-8.

Copyright (C) 2001 Massachusetts Medical Society. 